\title{
Surface Finish of Dental Composite Restorative Materials
}

\author{
L. G. TOLLEY, W. J. O'BRIEN, and J. B. DENNISON, \\ University of Michigan, School of Dentistry, Ann Arbor, \\ Michigan 48104
}

\begin{abstract}
Summary
Five composite filling materials were finished using six finishing procedures currently in clinical use. The average roughness produced by each procedure was measured by means of a Surfanalyzer with four replications for each procedure on each of the five materials. Statistical analysis indicated that finishing with silicon carbide disks produced the smoothest surfaces. Acceptable surfaces were obtained with stones or with burs. Use of an alumina paste after a green stone-white Arkansas sequence did not produce a significant improvement.

Two processes of filler particle abrasion were distinguished by means of electron microscopy: wear and shear. Fracture striations indicated particle shear.

The roughest surfaces were produced by the use of a diamond instrument which is contraindicated. Acceptable finishing procedures for the composite materials tested include silicon carbide disks for accessible areas or 12 fluted finishing burs for more inaccessible areas.
\end{abstract}

\section{INTRODUCTION}

The surface finish of composite materials is an important clinical consideration. ${ }^{1,2}$ Generally, it is difficult to polish these materials since the ceramic particles are much harder than the polymer matrix. A previous study showed that only composites polymerized against a Mylar matrix without additional polishing were as smooth as polished amalgam. ${ }^{3}$ Since previous studies were published, improved and new composites have become available. It was the purpose of this study to determine the relative effects of finishing procedures on currently available materials.

\section{MATERIALS AND METHODS}

Five commercial composites were studied: Adaptic (A) (Johnson and Johnson Co., New Brunswick, N.J. Batch \#5F101, DRS-201),

Journal of Biomedical Materials Research, Vol. 12, 233-240 (1978)

(c)1978 John Wiley \& Sons, Inc.

$0021-9304 / 78 / 0012-0233 \$ 01.00$ 
TOLLEY, O'BRIEN, AND DENNISON

TABLE I

Average Surface Roughness Values for Composite Materials

\begin{tabular}{cc}
\hline Material & Mean $(\mu \mathrm{m})$ \\
\hline DRS-201 & $1.00\}$ \\
Adaptic & 1.30 \\
Nuvafil & 1.35 \\
Simulate & 1.51 \\
Concise & 1.48 \\
\hline
\end{tabular}

Note: Values connected by same vertical line are not significantly different at the 0.05 level.

(D) (Drateck, Santa Ana, Calif. Batch \#62711), Simulate (S) (Kerr, Romulus, Mich. Batch \#75-32.58), Concise (C) (3M Co., St. Paul, Minn. Batch \# 419617), and Nuva Fil (N) (L.D. Caulk Co., Milford, Del. Batch \#73354. Six finishing procedures and a control were employed. The composites were mixed according to the manufacturer's instructions and placed into molds drilled into Plexiglas 6.35 $\mathrm{mm}$ in diameter and $1 \mathrm{~mm}$ deep. After filling each mold to excess, a Mylar strip was pressed down on the surface by means of a glass plate. A flash of composite was produced by extrusion of the excess composite material out of the mold cavity. The composite samples were allowed to cure for $1.5 \mathrm{~min}$ and then stored for $24 \mathrm{hr}$ at $37^{\circ} \mathrm{C}$ prior to finishing. The following finishing methods were employed.

1) Green stone (Medium Grit Silicon Carbide, No. F3, Chayes Virginia Lab. Prod., Evansville, Ind.) followed by white stone (Fine Grit Aluminous Oxide, No. 36P, Chayes Virginia Lab. Prod.).

2) Adalox fine disks (E. C. Moore Co., Dearborn, Mich.) followed by waterproof fine silicon carbide disks followed by waterproof $\mathrm{X}$ fine silicon disks.

TABLE II

Average Surface Roughness Produced by Finishing Methods

\begin{tabular}{lc}
\hline Finishing Method & Mean $(\mu \mathrm{m})$ \\
\hline Silicon Carbide Disks & 0.84 \\
Midwest American 12 Bur & 1.13 \\
Green stone-white stone & 1.26 \\
Green \& white stone-Alumina & 1.27 \\
Midwest American 40 Bur & 1.33 \\
Diamond Instrument & $2.90 \mid$ \\
\hline
\end{tabular}

Note: Values connected by same vertical line are not significantly different at the 0.05 level. 


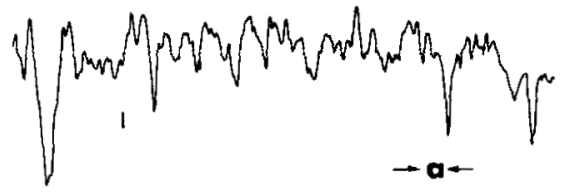

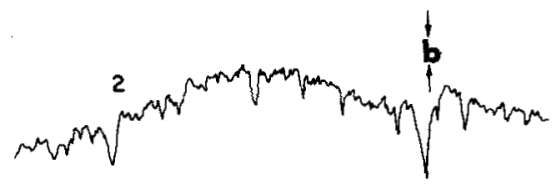

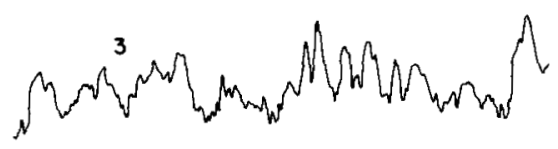

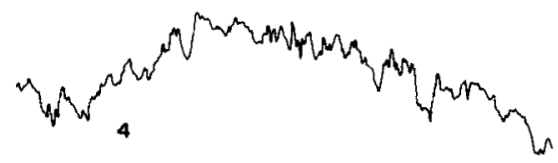

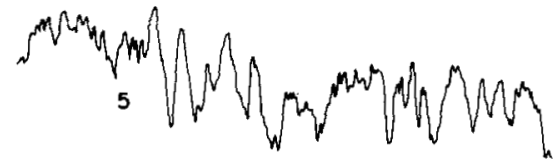

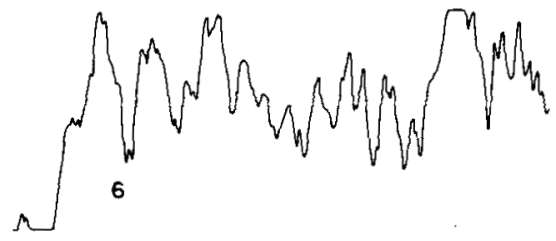

Fig. 1. Roughness profiles of surfaces finished with (1) green stone followed by white stone; (2) silicon carbide disks; (3) 12 fluted bur; (4) 40 fluted bur; (5) green stone followed by white stone followed by alumina paste; (6) diamond instrument. $a=50 \mu \mathrm{m}$; $\mathrm{b}=2 \mu \mathrm{m}$.

3) Twelve fluted finishing bur (Midwest American, Chicago, Ill.) (carbide).

4) Forty fluted finishing bur (Midwest American) (carbide).

5) Green stone followed by white stone followed by alumina polishing paste (Johnson and Johnson Co.). 


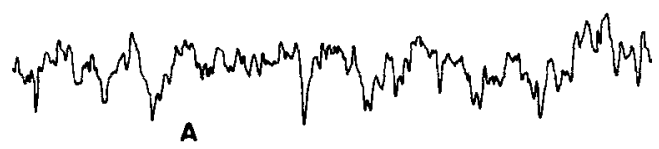

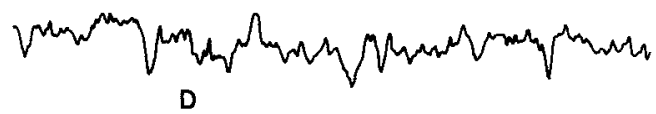

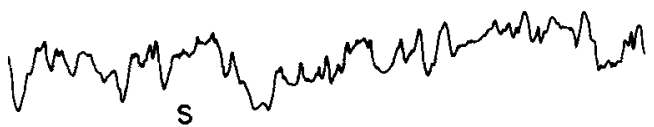

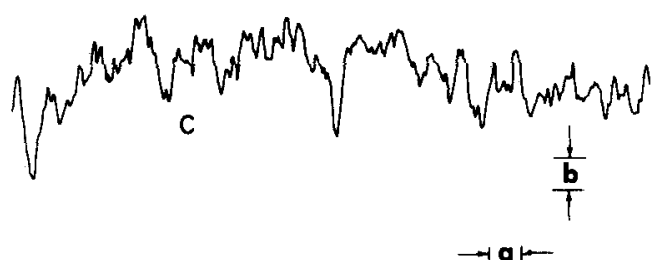

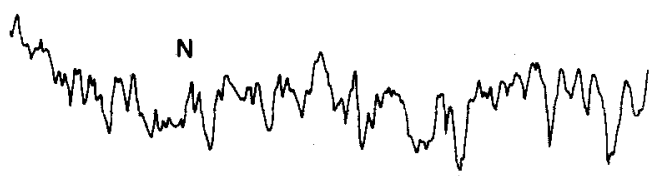

Fig. 2. Roughness profiles of finished composites: (A) Adaptic; (D) DRS; (S) Simulate; (C) Concise; (N) Nuva Fil. $a=50 \mu \mathrm{m} ; \mathrm{b}=2 \mu \mathrm{m}$.

6) Diamond instrument (Star Dental Mfg. Co., Philadelphia, $\mathrm{Pa}$.

7) Silicon carbide metallurgical power, number 600 (3M Co.). This served as a control since the finish produced was relatively independent of operator variation.

A Surfanalyzer (Gould Inc., Cleveland, Ohio; Model 160) was used to measure the surface roughness. A stylus radius of $2.5 \mu \mathrm{m}$ was used. A profile tracing was obtained with each sample and the average roughness in micrometers obtained. The entire sample selection procedure was randomized in regard to both materials and finishing 


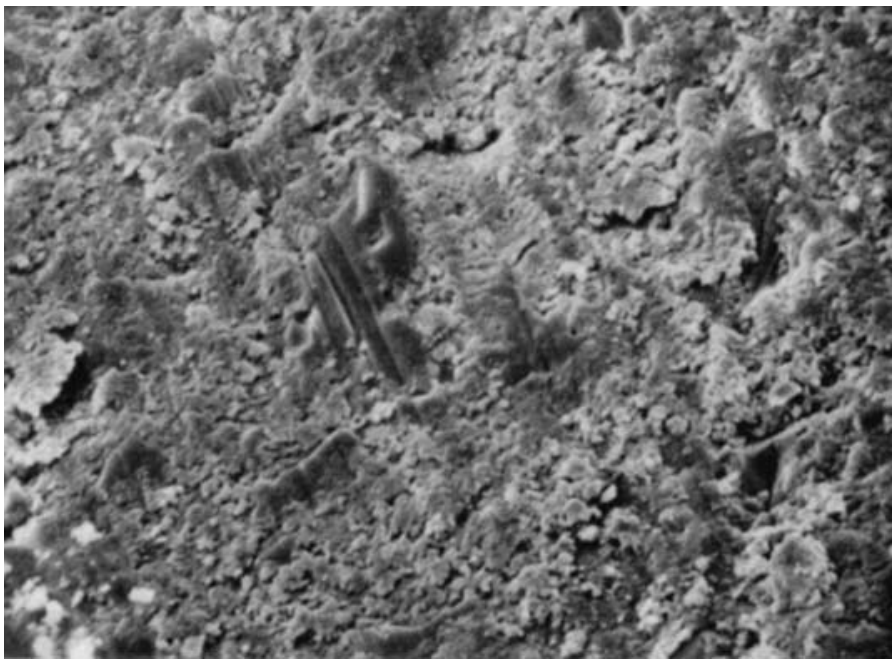

Fig. 3. Surface of DRS finished with sequence of green stone-white stone $(800 \times)$.

methods. A Student-Newman-Keuls multiple-comparison test ${ }^{4}$ was applied at the $0.05 \%$ level.

Selected samples were examined by scanning electron microscopy.

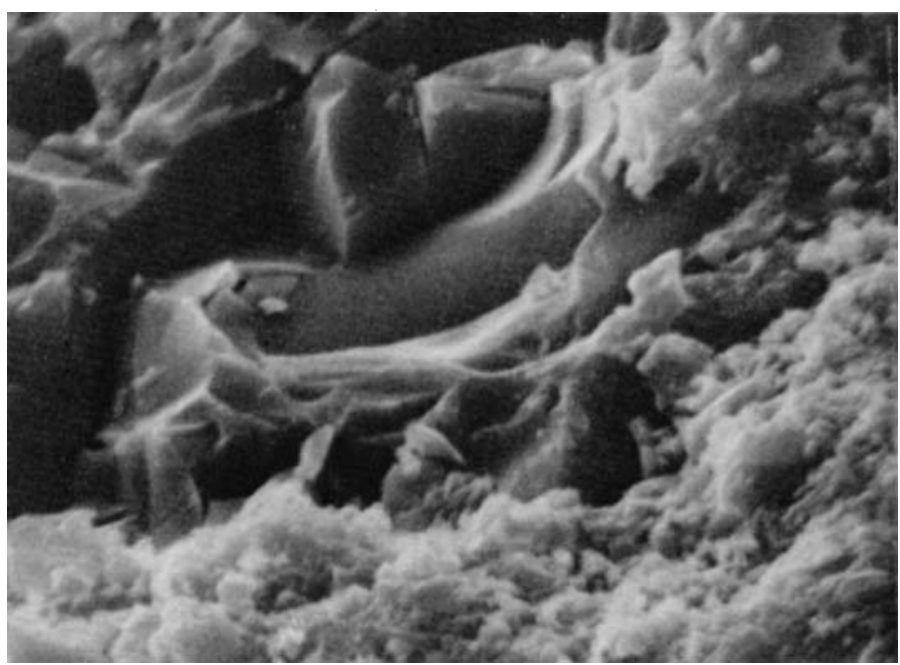

Fig. 4. Selected area of surface shown in Fig. 3 showing concoidal fracture of filler particle $(4800 \times)$. 


\section{RESULTS}

\section{Roughness}

The average roughness values of four replications for combinations of methods and materials were calculated. The materials are ranked in order of roughness in Table I with DRS-201 the smoothest. Table II ranks the polishing methods in roughness. There were significant differences between the materials and finishing methods, as indicated in Tables I and II. The control polishing technique using metallurgical paper yielded a mean value of $0.81 \mu \mathrm{m}$.

The results indicate that the smoothest surfaces were produced by silicon carbide disks followed by the 12 fluted bur and stones, while the roughest surface finish was produced by the diamond instrument. There was no significant difference between the surfaces produced by methods $1,3,4$, and 5 or between method 2 and the metallurgical paper. Finishing with the 12 fluted finishing bur produced surfaces not significantly rougher than those produced by method 1. Use of alumina finishing paste did not significantly improve the finish produced by use of a green stone-white stone sequence. The 40 fluted

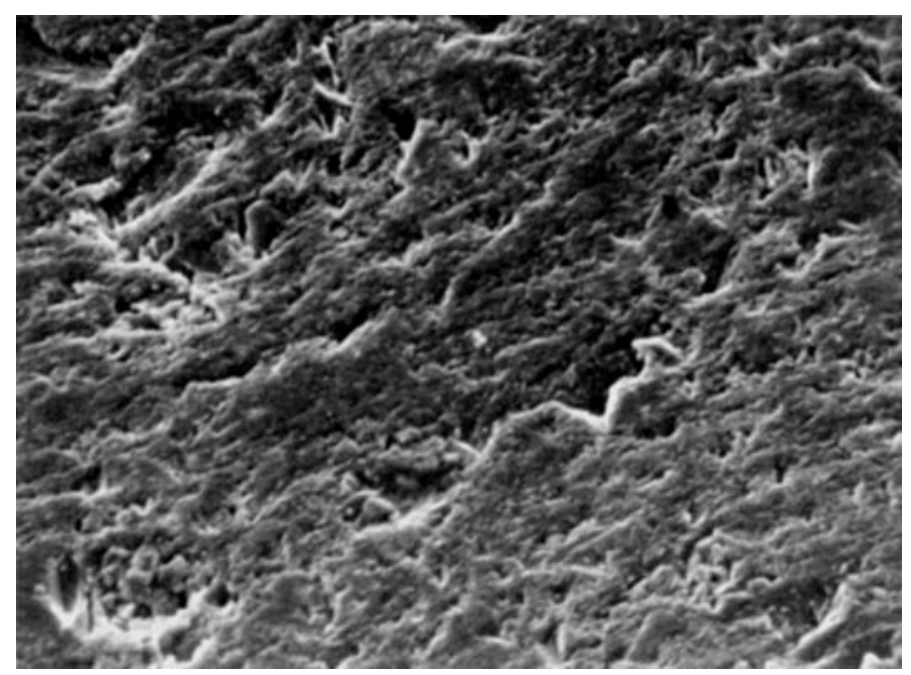

Fig. 5. Surface of Simulate finished with green stone-white stone sequence $(800 \times)$. 


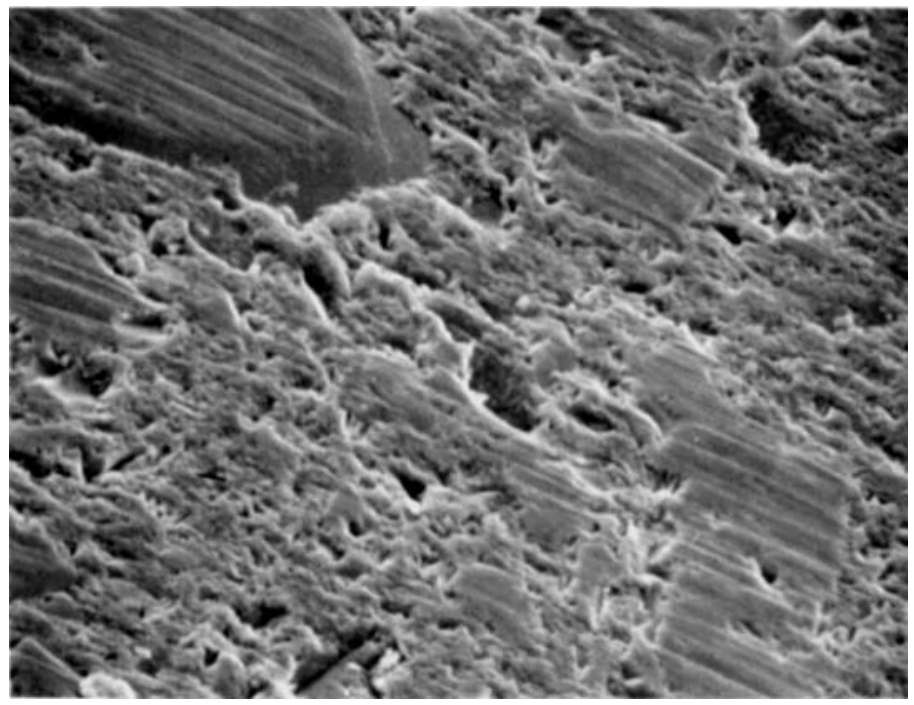

Fig. 6. Surface of DRS finished with silicon carbide disks ( $800 \times)$.

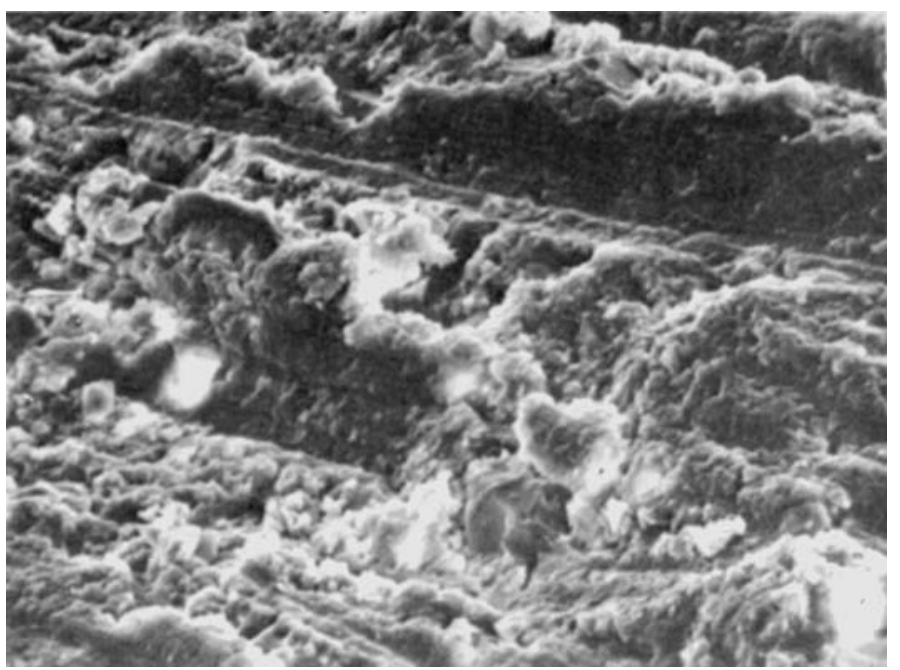

Fig. 7. Surface of Simulate finished with diamond instrument $(800 \times)$. 
finishing bur produced surfaces not significantly rougher than the green stone-white stone sequence or methods 3 and 5 .

Typical roughness profile curves for different methods are shown in Figure 1 and for the five composite materials in Figure 2.

\section{Microstructure}

Scanning electron micrographs showing surfaces produced by finishing are shown in Figures 3-7. Surfaces of D. R. S. were distinct in appearance after finishing and are shown in Figures 3 and 4. Fracture striations of filler particles are clearly visible in Figure 4. Surfaces produced by methods 1 and 2 are shown in Figure 5 and 6 . The surface produced by finishing with a diamond instrument is shown in Figure 7, indicating deep and broad abrasion tracks. Because of the high roughness produced, the use of diamond instruments are contraindicated for composites.

It is interesting to note that the average roughness obtained with the number 600 metallurgical paper of $0.81 \mu \mathrm{m}$ was close to that obtained with the silicon carbide disks $(0.84 \mu \mathrm{m})$. Dennison and Craig ${ }^{3}$ reported values of $0.84 \mu \mathrm{m}$ and $0.89 \mu \mathrm{m}$ for the same paper and disks, respectively. Since the metallurgical paper has a silicon carbide abrasive, a similar roughness value would be expected. However, these results indicate that the surface finish obtained is mainly a function of the abrasive used.

\section{References}

1. H. L. Lee, Jr. and M. L. Swartz, J. Dent. Res., 49, 149 (1970).

2. L. N. Johnson, J. A. Lynn, and R. E. Jordan, J. Am. Dent. Assoc., 83, 321 (1971).

3. J. B. Dennison and R. G. Craig, J. Am. Dent. Assoc., 85, 101 (1972).

4. R. R. Sokal and F. J. Rohlf, Biometry, W. H. Freeman Co., San Francisco, 1969, p 239.

Received February 11, 1977

Revised June 17, 1977 